\title{
Investment in Health; how should the government think and plan?
}

\author{
Dr Nuwadatta Subedi \\ Associate Professor, \\ Department of Forensic Medicine, Gandaki Medical College, Pokhara \\ E mail: drndsubedi@gmail.com
}

Healthy citizens are the pillars of national economy. Improvement of general health of the people is vital in improving the economy of a country. The government should invest in health care facilities and empower health care providers. This would enhance the people for the better access to health care to combat illnesses thus decreasing the financial burden related to health care. People would be involved more in work to increase the productivity of the country.

In recent years, the government of Nepal seems to attempt to enhance the health care sector. Under the development plans, the government has planned to ensure free basic health services and setting up health centers with at least one doctor across all local governments. Recently the government has launched insurance policy for the people. But the utility of the scheme is still in the phase of systematization. There are not adequate quality health care providers for the insured people. Only the government hospitals are allowed to initiate the treatment and they can refer to the private sectors if there are no treatment facilities in the center. This has led to concentration of the clients in those centers and are not fully satisfied with the facilities. There have been several challenges for the proper implementation of the program, including accreditation mechanisms for private providers. ${ }^{1}$

Although budget for health sector in Nepal is increasing in the recent years, it is still far below that of developed countries. To make a comparison, the United Kingdom spends about $10 \%$ of GDP in health sector and the United states around $16 \%$. Whereas in Nepal, it is around four percent only. There is also problem with implementation of the planned programs and utility of allocated budget in Nepal. However, there are many countries that spend less than Nepal in health care deliveries. ${ }^{2}$ The health care expenditure of countries varies from one to well over 10 percent of the total GDP. There are several factors for the allocation of budget for health sector including peer pressure, political economy, production function and the budgeting approaches. The government has to analyze the goal to achieve based on the approaches and determine the proper budget for the health sector. ${ }^{3}$

Government has to invest in the health of the people. Healthy people will generate economy to the nation by making more production and paying tax to the government. Taking this issue into consideration, many developed countries fund the health sectors and bear health care expenditures of their people. Among the OCED countries, Norway tops the list by providing the highest government fund for the total health expenditure comprising $85.2 \%$ of the expenditure government whereas in the USA it is $49.1 \%$. The expenditure consists of the provision of preventive and curative health services, activities for family planning, nutrition and emergency aid targeted for health. It does not include the provision of water and sanitation. ${ }^{4}$ 
The government should work to minimize work related injuries. Strict regulation should be made for the compulsory use of protective equipment in the workplace. Construction of proper roads not only minimizes road traffic accidents but also provides easy access to the health care facilities when people are sick or injured and have to be taken to the hospital soon. Development of health care facilities is not the only way of making the people healthy. It is just a curative measure. The nation should strive to prevent diseases by minimizing pollution and encouraging the people to opt healthy lifestyle. There should be adequate open spaces in the cities for the facilitation of mobility of people. Parks should be constructed in the residential areas and exercise spots and equipment should be installed so that the people are encouraged to perform physical activities and get access to the facilities. Peoples republic of China has constructed public exercise spots for free in every corner of the country. People are sensitized to perform physical activities and opt healthy living. The existing government of China has worked to shift the focus of their people from luxury goods and wealth to more valuable for life: their health and has been very successful in the attempt.

In conclusion, healthy people are wealth of the nation, thus the government should do all the efforts for making the people healthy which increases the productivity and enhance the national economy.

\section{REFERENCES:}

1. Mishra SR, Khanal P, Karki DK, Kallestrup P, Enemark U. National health insurance policy in Nepal: challenges for implementation. Glob Health Action. 2015 Aug 21;8:28763.

2. Countries who spend the least on healthcare. [cited 22 June 2019]. Available from: https://www.worldatlas.com/articles/the-countrieswith-the-lowest-health-expenditures-in-the-world-relative-to-gdp.html

3. World Health Organisation. How much should countries spend on health? Discussion paper, Number 2/2003. [cited 22 June 2019]. Available from: https://www.who.int/health_financing/documents/cov-dp_e_03_2-how_ much_to_spend/en/.

4. OECD. "Health spending" (indicator). 2019. [cited 22 June 2019]. Available from: https://doi.org/10.1787/8643de7e-en. 